\title{
OS VERDADEIROS AMIGOS NA RAIA MIÑOTA: OS COGNADOS
}

Helena Pousa Ortega

IES San Paio - Tui 

De um lado terra, doutro lado terra; De um lado gente; doutro lado gente; Lados e filhos desta mesma serra,

O mesmo céu os olha e os consente.

Miguel TorgA, «Fronteira»

\section{BREVES ACHEGAS HISTÓRICAS NA FRONTEIRA COMUNICANTE: A PERMEABILIDADE CONFLITIVA}

Para comprender a evolución lingüística na raia mollada, na fronteira comunicante ou fronteira porosa, nomes que lle teñen dado en diferentes ocasións, quero destacar brevemente algúns acontecementos históricos que perfilaron as características desta área, na que se mantivo unha certa comunidade, que xa vińa existindo desde moito antes das invasións nórdicas nos séculos IX, X e XI d.C., das cales nos quedou como herdanza o barco carocho ${ }^{1}$ co que se pescou e se permitiu o trafego dunha ribeira a outra, nas que a veciñanza era un dos motores principais da economía local.

Dos séculos XII ao XVII, desde a Pax de Tui á Pax de Lisboa, cómpre destacar que se estableceu unha fronteira política que nunca foi recoñecida polos da banda de alén Miño. Na época de Afonso VII e Fernando II houbo continuas liortas e incursións coa fin de recuperar terras aquén Miño, ricas en vińas e comercio. Nunca foi aceptada de bo grado por don Afonso Henriques e, aínda que asina o Tratado de Tui ou Pax de Tui en 1137, non deixa de penetrar nas terras fronteirizas do seu curmán en diferentes ocasións. Igualmente os seus descendentes se resistiron a quedar trabados nesta lińa fronteiriza e non renunciaron a facer novas

Segundo mantén Mörling (1989), o seu deseño pode procede dalgún barco aquí abandonado tralas invasións viquingas de Olav Haraldsson. 
expedicións para capturar as vilas próximas (Salvaterra, A Guarda, Baiona...) que ora estaban baixo o dominio do rei leonés, ora dependían do rei portugués².

Paralelamente tamén convén lembrar que na Idade Media existiu un poderoso poder eclesiástico que permaneceu alleo a esta divisoria política. A súa xurisdición estendíase entre dous reinos ata terras de Braga, de onde procedían a maioría dos seus bens, ata que os bispos tudenses - moitos deles anteriormente de orixe portuguesa- comezaron a ser nomeados por Roma e polo Rei ${ }^{3}$.

En séculos posteriores, as vilas fronteirizas continuaron a ser albo da discordia. A partir do século XVII perfilouse de xeito militar a fronteira entre os dous Estados con motivo da guerra da Restauração, e edificáronse unha cadea de fortalezas abaluartadas, opostas e visibles entre si, en lugares estratéxicos dun e doutro lado, desde Crecente e Melgaço ata A Guarda e Caminha. Durante a época de D. João IV e D. Afonso VI ora pertencían a Portugal ora a España, ata a sinatura do Tratado de Lisboa (1668) co que se puxo fin ás hostilidades, e se restituían as prazas tomadas durante a guerra de restauración portuguesa aos seus respectivos reinos ${ }^{4}$.

2 Non hai ningún sucesor de Afonso I que non devecese por pór cerco a Tui. Nomeadamente canda os problemas sucesorios, a cidade foi un niño para os petristas ou partidarios de D. Pedro. O mesmo don Pedro, conde de Barcelos, estivo en Ganfei como «fronteiro do Minho» pois a tensión provocaba a vixilancia permanente. D. João I atravesou o Miño en ocasións diferentes, e sempre escollía o día da festa de Santiago para tomar a cidade, en 1389 e en 1398, que permaneceu en poder do monarca ata 1402 . Nun foro datado o 19 de xullo de 1404, transcrito por Vila-Botanes (2001: 49), pertencente á documentación capitular da catedral tudense (Prot. Libro viII, fol.136, 1424, 4 de marzo), pódese observar claramente como toda a zona aquén Miño está en mans dos portugueses «Por rasom que enas guerras que nosso sennor el rey de castella ouvera con o aversario de portugal a çidade de Tuy e as villias de Bayona e da Guarda e de Salvaterra e de Ribadavya e esta terra toda de Toronho por la mayor parte foram tomadas e conquistadas por lo dito aversario e teveram em seu poder a dita çidade e a dita villa de Salvaterra por espaço de çinquo annos e mays e a dita villa de Bayona por espaço de dous anos e que en estas tomadas e estadas que esteverom por los ditos ynimigos». Segundo resalta o mesmo historiador (Ib.), a tensión fronteiriza prolongouse durante varios séculos e era o pan de cada día ata que comezou o total dominio dos Soutomaior no século XV.

3 «Entre os anos 1423 e 1427 vaise prolongar na diócese tudense un conflito eclesiástico que atinxía o nomeamento do bispo tudense. O cabido tińa, ata o de aquela, a potestade de elixir un prelado para a diócese e presentalo a Roma. Porén, 1423 será o derradeiro ano no que se poida facer esta elección, a partires de aquí, Roma e o Rei de decidirán sobre o nomeamento do bispo tudense (como doutras dióceses)» (Vila-Botanes 2001: 60). Tamén cabe destacar que, por apoiaren o papa Urbano VI e non o papa de Avińón, tiveron moitos problemas. Os cismáticos chamados chamorros, refuxiáronse en Valença e alí permaneceron durante un tempo os cregos sediciosos que foron excomungados.

4 Garrido Rodríguez (1987: 207-211) e Fernández Rodríguez (1995: 29-44). Moitos historiadores teñen moi en conta a obra do Conde de Ericeira (1947: 437-453) e as novas publicadas no xornal propagandístico O Mercúrio Portuguez (1663-1667), dirixido por António de Sousa de Macedo, publicado no con- 
O certo é que o continuo estado de guerra condicionou de novo o desenvolvemento histórico, económico e cultural desta zona. As razzias cometidas, a pillaxe, a destrución desenfreada, coartaron ou impediron un maior crecemento das vilas nas súas ribeiras, fortemente empobrecidas por un conflito bélico que deixou moitos mortos tamén nesta zona.

E segundo avanzan os séculos e se afortalan os 'estados modernos', o que en realidade era un espazo natural, dividiuse de maneira artificial e impúxose unha barreira invisible e poderosa, unha lińa imaxinada que, segundo comenta Vila-Botanes (2001: 247), acadará que ambas as beiras sexan incapaces de se recońeceren por causa desa barreira máis mental ca real «ocupando o temor e a desconfianza a antiga viciñanza».

A pesar da maior restricción e control da mobilidade das persoas, que se intensificaron a partir da metade XVIII, un elemento que mostra a permanente permeabilidade da raia mollada, ademais do comercio, son as migracións que xa están documentadas desde a Idade Media ${ }^{5}$ e que se reactivan a partir dos séculos XIX-XX: galegos para Portugal, portugueses vindos a Galicia. A mobilidade galega a finais do XVIII e inicios do XIX, cunha das máis altas densidades demográficas da península ibérica, deuse entre persoas novas xa casadas, maiormente para Lisboa. No Alto Minho entre 1879 e 1899 fixáronse emigrantes oriundos da Guarda ${ }^{6}$, Camposancos, Salcidos, O Rosal, Tabagón, Tomiño... que asentaran no litoral, con particular incidencia en Vila Praia de Âncora e Caminha. En Âncora fixouse unha pequena comunidade piscatoria que deu inicio á actividade marítima, factor que colocará esta vila nun dos lugares cimeiros dos portos portugueses.

A par desta emigración, maiormente entre 1880 e 1930, prodúcese unha nova enxurrada migratoria cara alén mar, especialmente ao Brasil, un lugar atraente e descońecido ao que van en busca dun maior éxito económico, que en moitos casos conseguen. Cando retornan os brasileiros de torna-viagem, moitos son

texto da guerra pola independencia de Portugal. Nos seus artigos nárranse feitos sucedidos nestas terras da raia mollada e como os portugueses preparan os ataques e conquistan os fortes, e saquean lugares como a vila da Barca (Goián) en outubro de 1663.

5 «No entanto, pelo menos desde o século xIV que existia entre as freguesias da raia a prática da vicinalidade dupla: portugueses e galegos desfrutavam indistintamente do estatuto de vizinhos nas vilas fronteiriças, embora estas relaçôes se dessem com mais intensidade entre as povoaçôes mais próximas. La Guardia e Goyan com Caminha são disso exemplo» (Rego 2009: 155).

6 «Em 1825, foi detetada a presença de um pescador galego na paróquia, de nome António Verde, oriundo de A Guarda» (Rego 2013: 13). 
emigrantes «ilustrados» e traen obxectos exóticos, froitas, plantas, árbores, novos costumes e ideas, e sotaques brasileiros. E no seu afán de mostrar o seu triunfo e a súa nova posición social constrúen vivendas fermosísimas, escolas, sociedades recreativas, que constitúen todo un exemplo de arquitectura indiana no Baixo Miño7.

Da parte portuguesa viñan traballar para o Baixo Miño moitos pedreiros e serradores - moitos deles da zona de Coimbra, de Souto da Carpalhosa (Leiria) ou de Leça da Palmeira (Matosinhos)-, como empregados nas empresas madeireiras, para serraren os toros dos piñeiros cos cimbróns. Outros portugueses viñan traballar como morrilleiros (nas estradas), como criados das casa de labranza, carretadores, etc. Aquí asentaron, aquí casaron, e hoxe en moitísimas familias é frecuente encontrar apelidos portugueses dos familiares vindos de alá.

E, máis recentemente, trala guerra civil, outro feito que destaca sobranceiramente é a actividade do contrabando -denominado como o pisco, o trapiche, a sucata-e as actividades comerciais clandestinas compartidas por xentes de unha e outra banda. Alén de café, améndoas e produtos necesarios, traficaban con chapa de cobre, lingotes de ouro, volframio... Os portugueses, neses anos de miseria, viñan vender panos e tecidos que ofrecían desde o barco carocho como vendedores ambulantes sen tan sequera atracar na beira galega. Daquela houbo, ademais, outro tipo de contrabando: o paso clandestino dos fuxidos, perseguidos polos falanxistas nos anos da guerra civil, e os que o fixeron en sentido contrario para fuxir da ditadura salazarista ou da tropa.

En resumo, en tantos séculos de convivencia, o río co seu maino discorrer nunca tivo vocación de ser unha raia. Sempre houbo, unhas veces xuntos, outras veces separados, polas boas ou polas malas, intercambios comerciais, laborais e sociais de xeito diferente a outros lugares fronteirizos, sen que se percibise unha fonda fractura nin cultural nin lingüística. Non se pode afirmar que a nivel léxico -e en parte a nivel morfolóxico- haxa unha isoglosa lingüística de separación total. O que encontramos son moitas isoglosas que se reparten de xeito arbitrario, e non só entre a banda de aquén e alén Miño, senón tamén internamente en cada unha das marxes.

\footnotetext{
7 Martínez Pousa (2009) realizou unha pormenorizada catalogación das construcións indianas da zona do Baixo Miño galego, na que inclúe, ademais das vivendas familiares, todas aquelas construcións que foron custeadas por capital americano dos emigrantes ou polos seus herdeiros.
} 


\section{UN TRILLO LINGÜÍSTICO POLA RAIA: MOTIVOS E OBXECTIVOS DO ESTUDO}

É evidente que entre o galego e o portugués hai moitas semellanzas e temos común moito léxico, que convén restaurar ou salvar. Neste artigo quero mostrar algunhas das afinidades no espazo fronteirizo do Miño - desde Salvaterra e Monção cara á desembocadura-, pois creo que non é bo nin rendible para a lingua meter o dedo na suposta chaga das nosas diferenzas insalvables.

Nesta investigación feita nas localidades máis próximas da raia mollada, non

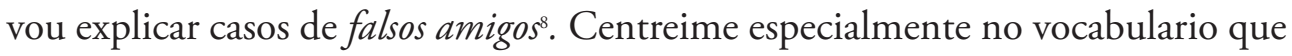
temos en común, nos verdadeiros amigos, os chamados cognados, para mostrar como aínda se mantén unha certa comunidade lingüística, como partillamos un vocabulario que, infelizmente, na parte galega corre o risco de se perder a moita máis velocidade ca na outra marxe, por razóns sociolingüísticas e por estar fóra do estándar.

A maior parte das palabras foron recollidas en enquisas feitas en distintas parroquias e freguesías', tal como se pode observar no Mapa 1. Para a elaboración do cuestionario tiven en conta os xa feitos para o $A L G a$ e o $A L E P G$, e tamén o vocabulario que aparece en glosarios, documentos ou obras etnográficas que recollen léxico desta zona ${ }^{10}$. Moitas das palabras ata agora investigadas estaban relacionadas con aspectos etnográficos do mundo rural e marińeiro.

8 Nalgúns traballos insístese nos chamados falsos amigos entre dúas linguas. Moitos están feitos desde a perspectiva do español respecto do portugués, e á inversa, para lograr unha maior corrección á hora de utilizar un ou outro idioma (vaso/copo, oficinaltalher, bola/balâo...). Cómpre pór atención neste tipo de listas porque desde a perspectiva do galego non se poden catalogar do mesmo xeito moitos dos exemplos citados, posto que temos unha maior igualdade semántica tal como sucede, por exemplo, entre virar/xirar ou rico/bo.

9 Para este traballo elaborei un cuestionario específico que fun preguntando a persoas dos distintos concellos situados á beira do Miño. Os e as informantes do Baixo Miño (BM) das parroquias de Camposancos e A Guarda (concello da Guarda), das Eiras (O Rosal), de Goián (Tomińo), de Malvas e A Guía (Tui). Na parte portuguesa, o vocabulario obtido procede de persoas das localidades de Caminha (no concello de Caminha), Campos e Sopo (Vila Nova de Cerveira) e Cerdal e Ganfei (Valença). Noutros concellos fronteirizos como Salceda de Caselas (Soutelo, Entenza), Salvaterra de Miño (centro e Porto) e Monção, unicamente preguntei parte do cuestionario. Tamén teńo en conta o vocabulario xa recollido en anos anteriores para outros traballos no concello de Oia (Mabia).

${ }^{10}$ Das obras consultadas cabe destacar polo seu maior interese as seguintes: Alonso (1987, 1989), Boaventura (1916), García (1985), Guerreiro (2006), Sequeira (1957), Netto (1949), Ríos Panisse (1977). 


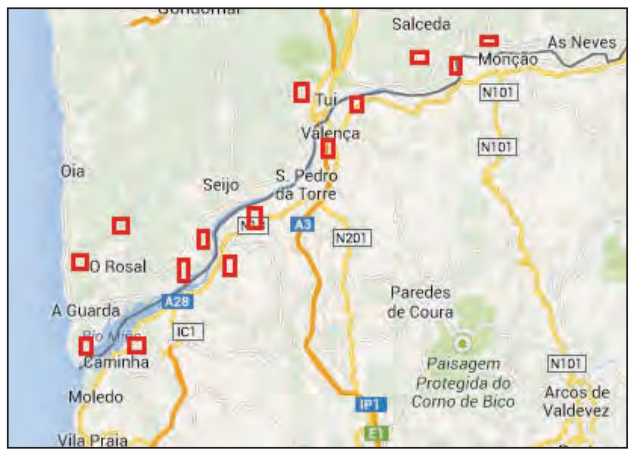

Mapa 1: Localización das enquisas

Trátase pois dun estudo feito desde a perspectiva da lingua oral dialectal a nivel sincrónico, e a pesar do declinio do mundo rural tradicional e dos seus modos de vida, moitas das palabras citadas aínda sobreviven aos fortes cambios socio-económicos. Coas enquisas puiden comprobar que non pertencen a un repositorio diacrónico e son coñecidas por persoas maiores de entre 50 e 80 anos. O que si é certo é que a súa vitalidade é fráxil e moitas delas non van poder resistir aos cambios tan rápidos nos modos de vida que se producen nas novas xeracións dunha banda e da outra.

Despois de peneirar o material léxico encontrado, cotexei a súa existencia e os seus significados en diferentes dicionarios ${ }^{11}$, e descubrín que moitas desas palabras aínda non aparecen recollidas en ningún ou só se citan nalgúns dos dicionarios consultados, ou que teñen algún significado que aínda non se sinala, mais isto non quere dicir que non sexan usadas por máis falantes, e noutros lugares.

Co fin de poder delimitar esta análise lexical, decidín centrar a investigación do vocabulario, tal como xa fixen noutros traballos (Pousa Ortega 2002 e 2004), nuns cantos campos léxicos ou esferas semánticas, que indico máis adiante, sen facer pescudas etimolóxico-documentais. A maior parte do léxico está ligado á cultura material aínda que tamén fixen algunha incursión noutro tipo de léxico máis abstracto e tentei explorar a semellanza polisémica en parellas de palabras como fogo-lume, empurrar-puxar.

\footnotetext{
${ }^{11}$ Entre os dicionarios consultados están: Costa / Melo (1979), Figueiredo (2007), Ferreira (2010), Santamarina (2006-2013), Carballeira (2000), Houaiss (2011) e Estraviz (2005).
} 
Entre os temas sobre os que procurei información destaco os seguintes, por seren os que máis traballei ata hoxe na busca de información léxica:
1. Mundo da pesca
a. A pesca no río
b. A pesca no mar
c. A recolla do argazo

2. Mundo agrícola

3. Cultivo da viña a. Outros cultivos

4. Territorio a. Elementos orográficos

b. As augas

c. As pedras

d. A división do territorio agrícola

5. Corpo humano a. Aspectos físicos

b. Adxectivos caracterizadores

\section{OS VERDADEIROS AMIGOS NA RAIA MIŃOTA}

Dado que hai moitos elementos léxicos que presentan a mesma forma entre o galego e o portugués, pero non participan sempre das mesmas características, vou centrarme naqueles vocábulos comúns que denominarei como 'verdadeiros amigos' para distinguilos dos chamados falsos amigos, coa intención de remarcar a sistematicidade dentro da variedade diatópica.

Cando abordamos a análise das palabras que presentan a mesma forma en dúas linguas podemos encontrarnos con varios conxuntos. Primeiro, distínguense os cognados ${ }^{12}$ que presentan unha orixe común e un mesmo (enorme) parecido formal e semántico. Segundo, hai vocábulos que son moi similares e normalmente teñen unha orixe común, pero non teñen ningunha amizade semántica, unicamente a grafía e a pronuncia son (practicamente) iguais. Estas palabras que

\footnotetext{
${ }^{12}$ Outro subgrupo dentro dos posibles cognados formaríano as parellas de homónimos, de orixe e significado diferentes que, en ocasións, non pertencen á mesma categoría gramatical. Dos 800 homónimos encontrados no VOLGa elaborado polo ILG e a RAG, unicamente podería ter en conta para este estudo uns 140 casos, como por exemplo: $c a n e l a^{1} / c a n e l a^{2}, c o c a^{1} / c o c a^{2}, m u d o^{1} / m u d o^{2}$, etc.
} 
se parecen no físico pero denotan cousas ben diferentes, son os cońecidos como «faux-amis», falsos amigos ${ }^{13}$.

Os cognados verdadeiros, stricto sensu, son facilmente recoñecibles, e hainos máis transparentes ou máis opacos. Neste grupo debemos incluír os préstamos, que entraron no galego desta zona a través do portugués: carocho, francesiña...

\begin{tabular}{|c|c|c|c|c|c|}
\hline \multirow{5}{*}{ 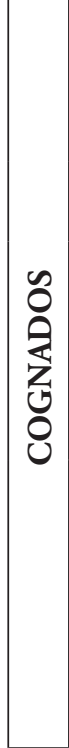 } & \multirow{3}{*}{ 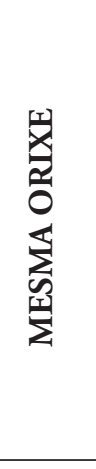 } & \multirow{2}{*}{$\begin{array}{l}\text { Cognados } \\
\text { verdadeiros: } \\
\text { mesma forma } \\
\text { (ou moi } \\
\text { semellante) }\end{array}$} & \multirow[t]{2}{*}{$\begin{array}{l}\text { xerais / } \\
\text { parciais }\end{array}$} & \multirow{2}{*}{$\begin{array}{l}\text { mesmo } \\
\text { significado }\end{array}$} & $\begin{array}{l}\text { toalla }(\mathrm{gal} . \mathrm{BM})=\text { toalha }(\text { de mesa } \\
\text { e de baño) } \\
\text { pescozo (gal. BM)= pescoço (de per- } \\
\text { soas e animais) }\end{array}$ \\
\hline & & & & & $\begin{array}{l}\text { carro (gal. BM) (cuncha do boi } \\
\text { ou centola) } \neq \text { carro (pt.) (automóbil) }\end{array}$ \\
\hline & & \begin{tabular}{|l|} 
Préstamos: \\
mesma forma \\
(ou case) e igual \\
pronuncia (con \\
lixeiras \\
adaptacións) \\
\end{tabular} & $\begin{array}{l}\text { visibles / } \\
\text { ocultos }\end{array}$ & $\begin{array}{l}\text { mesmo } \\
\text { significado }\end{array}$ & $\begin{array}{l}\text { bolaxa }(\text { gal. BM })<\text { bolacha }(\text { pt.) } \\
(\text { doce redondo con azucre por riba) }\end{array}$ \\
\hline & \multirow{2}{*}{ 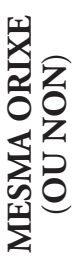 } & \multirow{2}{*}{$\begin{array}{l}\text { Cognados en- } \\
\text { ganosos - falsos } \\
\text { amigos }{ }^{14}: \text { mesma } \\
\text { forma }\end{array}$} & \multirow{2}{*}{$\begin{array}{l}\text { Perfectos } \\
\text { (idéntica } \\
\text { grafía) / } \\
\text { imperfectos } \\
\text { (grafía } \\
\text { próxima) }\end{array}$} & \multirow{2}{*}{$\begin{array}{l}\text { diferente } \\
\text { significado }\end{array}$} & $\begin{array}{l}\text { galleteiro (gal. BM) (que gusta das } \\
\text { galletas) } \neq \text { galheteiro (pt.) (utensílio } \\
\text { de serviço de mesa para sal, pimenta } \\
\text { e outros temperos) }\end{array}$ \\
\hline & & & & & $\begin{array}{l}\text { borracho (gal. BM) (que está em- } \\
\text { briagado, bebido) } \neq \text { borracho }(\text { pt.) } \\
\text { (pombo novo; homem bonito) }\end{array}$ \\
\hline
\end{tabular}

Cadro 1. Cognados (orixe)

\footnotetext{
${ }^{13}$ Nalgúns traballos estudáronse os diferentes tipos de falsos amigos (entre español e portugués), e os seus subconxuntos, como por exemplo Carita (1999). Non está nos obxectivos deste traballo analizar todas as posibilidades de clasificación que ofrecen os falsos amigos, pero de xeito resumido podemos catalogalos como perfectos (se non teñen nada en común) e imperfectos (se coinciden nalgunhas das acepcións e diverxen noutras). Humblé (2005-2006) sinala que «tradicionalmente se limita el problema a pares de palabras que son iguales pero significan otra cosa, [...] los verdaderos problemas causados por la proximidad de las dos lenguas están en diferencias de registro, de coincidencia parcial de los campos semánticos o de usos gramaticales diferentes».

${ }^{14}$ Outros nomes posibles son: faux-amis, deceptive cognates, heterosemánticos, falsos cognados... Pola súa parte, Cintra (1998: 137-138) distingue entre outros casos os cognados enganosos «que apresentam semelhança de forma mas não de significado (Ing. parent $\mathrm{x}$ Port. parente), e são frequentemente fonte de problemas para o aprendiz. Costumam ser chamados erroneamente de falsos cognados - na verdade são cognados verdadeiros que apenas diferem no significado. A expressão falsos cognados seria mais adequada para referir-se a palavras que apenas parecem ser relacionadas (como Ing. saber x Port. saber, It. burro x Port. burro, etc.)».
} 
De nos centrarmos nas palabras lexicais que presentan unha acepción e se refiren a un obxecto, a un elemento concreto, o traballo de identificación como cognados non é complexo, pero cando nos dedicamos a recoller palabras plurisémicas, xa esixe pór máis coidado. Calquera palabra que teña unha polisemia diferente nas dúas linguas pode ser designada ben como un cognado (parcial), ben como un falso amigo (imperfecto), como por exemplo carro (gal.): 1. Vehículo de transporte de dúas rodas e arrastrado por bois ou vacas. 2. Constelación. 3. Cilindro xiratorio para largar e recoller as redes. 5. Medida para áridos. 5. Peza da dorna. 6. Corpo da lagosta. 7. Cuncha dalgúns crustáceos (boi ou centola) sen as patas ${ }^{15}$. Sen expor todos os posibles significados desta palabra en ambas as linguas, pódese apreciar a súa heterosemanticidade, xa que o galego e portugués coinciden apenas nalgúns significados. Por exemplo, nas acepcións 1 e 6, pero non así na 7, utilizada no BM. E en galego tampouco ten o significado máis usual no portugués actual: «veículo de rodas para transporte de pessoas».

Por tanto, dado que a análise dos elementos léxicos comúns non se debe limitar á forma, ao significante, e require ademais unha fonda análise da heterosemanticidade, que non sempre está ben explicada nos dicionarios de uso, vou catalogar co nome de verdadeiros amigos todos aqueles vocábulos desta zona que son comúns na orixe, que pertencen á mesma categoría, ao mesmo nivel ou rexistro e posúen un mesmo significado ou comparten algunha(s) acepción(s), xa que presentan características ben diferentes doutros casos.

\section{COGNADOS}

\begin{tabular}{|l|c|c|c|}
\hline & transparentes & $\rightarrow$ & opacos \\
\hline Mesma orixe & + & + & + \\
\hline Mesma pronuncia & + & $+(-)$ & - \\
\hline Mesma grafía/forma & + & - & - \\
\hline Mesmo significado & + & + & + \\
\hline Mesma categoría gramatical & + & + & $+(-)$ \\
\hline Mesmo nivel de lingua & + & + & + \\
\hline
\end{tabular}

Cadro 2. Cognados (significado)

\footnotetext{
${ }^{15}$ No $D d D$ aparece este significado recollido unicamente por Otero na Guarda (do lat. CARYON) e por Ríos Panisse (1977: 58), tamén no Carril.
} 


\section{RESULTADOS}

Como xa comentei, a maioría dos resultados obtidos dependen maiormente do encontrado nas enquisas feitas ( vid. nota 9) nestes últimos anos a moitas persoas da zona ás que quero agradecer a paciencia e o interese mostrado. Non me limitei a recapitular o que se recolleu en estudos anteriores ou está cartografiado no $A L G a$. A pesar de ter localizado na parte galega palabras que aínda non están rexistradas, non as inclúo por non apareceren nas respostas dos enquisados portugueses, aínda que confío en que é posible que en futuras indagacións poida comprobar o seu uso común en ambas as marxes.

Nunha investigación deste tipo tamén considero importante ter en conta a predisposición mental e cultural dos habitantes da raia (mollada). Por iso, quero destacar que aparte de léxico, temos comúns moitos outros elementos como:

1. Solucións fonéticas

2. Elementos gramaticais/sintácticos

3. Elementos culturais (costumes, festas, datas importantes, toponimia, expresións feitas...)

\subsection{Elementos comúns ${ }^{16}$}

\subsubsection{Evolucións fonéticas}

- Metafonía de -o final en substantivos e adxectivos (no singular): corpo, ollo, soghro ( $\neq$ soghra); novo $(\neq$ nova $)$.

- Ditongo -ui-: muito, cuidar...

- Mantemento do elemento labiovelar $u$ en cuatro, cuando, cual, ghuardar..

${ }^{16}$ Para non complicar demasiado a exposición nesta epígrafe, só transcribo a forma galega coa grafía escollida na actual normativa e non pońo de novo a forma en portugués (ex. cuatro = quatro). Está claro que, mesmo cando a grafía é idéntica, a pronuncia está marcada polas diferenzas vocálicas na nasalidade ou pola sonoridade das consoantes sibilantes en portugués, pois é sobexamente cońecido que a fonética constitúe un dos nosos puntos de diferenciación. Nesta zona portuguesa non se perciben tanto outras oposicións como a de /b/e / $/ \mathrm{v}$ ou a pronuncia do $<\mathrm{ch}>$ como fricativa palatal xorda. Respecto da pronuncia con gheada, que transcribo con $<\mathrm{gh}>$, común no BM, é de notar a súa ausencia na parte portuguesa. 


\subsubsection{Elementos gramaticais}

a. Xénero dimensional: fouciño (+) / fouciña (-), machado (+) / machada (-), saco $(+)$ / saca (-), xanelo (-) / xanela (+), pipo (-) '8 cabazos' / pipa (+) 'uns 40 cabazos', caneco $(+) /$ caneca $(-) . .$.

b. Valores especiais dalgúns sufixos

- Sufixo -eiro, -a unitario, individualizador de un único elemento dentro de un conxunto (centeeiro, granceiro, ALGa: II 33, nalgúns puntos de Pontevedra (P19, 22, 25, 25a, 27, 30 e 32), herbeira, milleiro, palleira, peleiro, tomateiro...

- Sufixo -eiro, -a con valor cuantificador: tardeiro, terreo ladeiro, pequeneiro, grandeiro, terra sequeira.

- Sufixo - douro ('que está en condicións', 'que xa pode', con valor semellante ao participio latino de futuro; 'que ten'): apañadouro, chamadouro, operadouro, postouro... (ex. Non ten operadouro 'que non se pode operar')

- Sufixo -ica intensificador: choromica, fuchica, cheirica, lavarica...

c. Pronome persoal

- Pronome ele ( $A L G a$ : II 159, en P29 e noutros puntos na costa galega).

- Pronome tu suxeito (ALGa: II 151, no BM, galego do sur de Pontevedra, Ourense e bloque oriental).

- Teísmo (cómprotos) (ALGa: II 153, no BM e O21, O24 e Z2, Z3).

- Pronome persoal de CI le (díxenle, leveile), (ALGa: II 180, en Z2, Z3, Le5).

- Alomorfo o, a do pronome persoal átono como CD: cortoua, deixouo, haio, viua (ALGa: II 173, no BM e maioritario no galego oriental; e ALGa: II $174 \mathrm{e}$ 175 , no BM e noutros puntos do galego, especialmente gal. oriental).

d. Verbos

- Solucións na SNP da P5 do presente de indicativo: cantais ( $A L G a$ : I 2, no BM e gal. oriental); colleis (ALGa: I 46), partís (ALGa: I 140). Tamén o SNP -ndes: faendes, tendes, vindes...

- SNP no pretérito: -stes na P2 ( $A L G a$ : I 7, no BM e puntos no galego oriental), e -stes na P5 que conta cunha maior extensión por todo o territorio galego (ALGa: I 10). 
Alén diso, temos outras solucións semellantes como: dozoito (ALGa: II 290, en P31) - dozaoito (en P32 e P33); o indefinido niñún/niñunha (ALGa: II 258, en $\mathrm{P} 31, \mathrm{P} 32, \mathrm{P} 33$ ); o indefinido cualquer un; o indefinido neutro tudo (ALGa: II 276, en P23, P32, P33); as formas dos adverbios de lugar cá (ALGa: II 313, en P33) e lá ( $A L G a$ : II 316, en P33, P29a, P29 e O28); o uso da preposición en co verbo falar (xa falamos niso)...

\subsubsection{Elementos culturais (toponimia, costumes, festas, datas importantes...)}

a. Toponimia. Encontramos moitos topónimos iguais en ambas as marxes. Como exemplos podemos citar: As Aceñas (O Rosal), río das Señas ( - Aseñas) (en Tui) / Azenhas (en Monção, Vila Nova de Cerveira); Os Picóns (O Rosal) / Os Picóes (Valença); Paredes (en Tomiño) / Paredes (en Vila Nova); Tomada (moi abundante en todo o BM) / Tomada do Castanhal (en Valença); O Condado (en Malvas, Tui) / O Condado (en Valença). E moitos outros máis: Anta, As Barxes, Carril, Crasto, Couto, Cristelo(s), Gabin, etc. En lugares do río ou da costa tamén encontramos os mesmos nomes: Paracán (coñecido tamén como Outeiro, en Camposancos) / Paracão ( en Caminha); Camboa (en Camposancos, Oia, Caminha); O regho da Pisa (na Guarda), A porta da Pisa (Caminha); Roncadeira (na Guarda e Caminha); As Oliveiras ( Lobeiras, na Guarda e Caminha), A Insua, A Barra...

b. Festas comúns. Unha das romarías máis antigas é o Lanzo da Crus <o Lanço da Cruz> no luns de Pascua, que celebran conxuntamente os do Torrón (Tomiño) e os portugueses de Cristelo-Côvo (Valença) na Nossa Senhora da Cabeça, para abenzoar as redes de pesca. Varias embarcacións galegas e portuguesas acompañan os párrocos das dúas marxes que dan a beixar unha cruz aos presentes. As treboadas (cf. Fernández Santomé 2012), grupos de bombos que van polas casas nos días de festa. O levantamento do arco, en Tabagón (O Rosal) e A Guía (Tui), con motivos florais, na entrada da festa, seguramente de influencia portuguesa. A noite das cancelas ou dos carros, chamada a atrancada no Minho portugués. E non digamos os costumes culinarios por compartirmos produtos do río, como os debullos de sable <debulhos de sável>, <lampreia $>$, as sollas, os verdes ${ }^{17}$, etc.

\footnotetext{
${ }^{17}$ A palabra verdes $(\mathrm{sm} \mathrm{pl})$ non aparece en dicionarios galegos, en cambio si está rexistrada nalgúns dos portugueses como 'guisado de sangue de porco' ou 'iguaria com sangue de porco', co mesmo significado dado nesta zona.
} 
c. Costumes sociais: denominación de Tío (Ti) Tía (Tié) como tratamento de respecto ás persoas maiores ${ }^{18}$ : Ti Xuón, Ti Sé, Ti Lucas, Ti Benito, Tié Aughusta, Tié Albina. O uso da designación como parceiros (A Guarda, O Rosal) para os compadres; andar a rascar a asa ('facerlle as beiras a unha moza, facer namoro') semellante a arrastar a asa no portugués popular, etc.

\section{LÉXICO EN COMÚN. OS COGNADOS NOS DICIONARIOS}

De todo o léxico recollido a unha beira e outra do Miño sur, vou destacar dous tipos de elementos comúns: os préstamos utilizados no BM e os cognados.

\subsection{Préstamos}

Estas entradas non poden ser tratadas como casos de interferencias (non se dá a imposición dunha lingua A sobre a B) ou como lusismos porque non se fai por vontade de estilo, nin para procurar un rexistro máis coidado ou máis próximo ao portugués. Son préstamos necesarios claros: bolaxa (<bolacha, 'doce'), carocho ('barco do Miño'), cavaquiño ('instrumento musical de catro cordas'), chamborra ('cheminea'), corete (<coreto, 'palco da música'), socata (<sucata, 'ferro vello'), francesiña ('bocadillo de carnes variadas con queixo e un mollo especial por riba'), pisca-pisca ('sinal luminoso intermitente dos coches'), vira ('danza'). Quizais desde o Brasil: maxuxo ('chuchu, planta cucurbitácea'), goiabada ('doce de goiaba')...

\subsection{Outros cognados}

O vocabulario atopado, que analicei e cotexei en diferentes dicionarios ${ }^{19}$, e cun uso común nesta zona, pódese subdividir en catro grupos. Vexamos algúns exemplos:

${ }^{18}$ Segundo Sequeira (1958: 134) é «o tratamento dado a uma pessoa de respetabilidade, ou a desconhecido de aspecto respeitável».

${ }^{19}$ Entre os dicionarios galegos, destaco o Diccionario de Diccionarios da lingua galega $(D d D)$ e o Gran Diccionario Xerais da Lingua (2000) (GX). Moitos dos autores de dicionarios galegos que aparecen nos cadros deste traballo están incluídos no $D d D$. Canto aos dicionarios portugueses consultados, destaco, por ofreceren máis información sobre o vocabulario mińoto, o Dicionário da Lingua Portuguesa da Porto Editora e o Dicionário Aberto. 


\begin{tabular}{|c|c|c|c|}
\hline & Dicionarios galegos & Dicionarios portugueses & \\
\hline A & $\begin{array}{l}\text { Si rexistradas } \\
\text { (nalgúns) }\end{array}$ & $\begin{array}{l}\text { Si rexistradas } \\
\text { (nalgúns) }\end{array}$ & $\begin{array}{l}\text { areo }<\text { areio }>\text {; arghaceiro }- \text { a; arghidal } \\
(\sim \text { alghidar })<\text { alghidar }>\text {; barxe } \\
(\sim \text { barxa })<\text { varge }(\mathrm{m})(\sim \text { varja })>\text {; } \\
\text { unha chan }<\text { uma chã }>\text {; escampado; } \\
\text { leiva; morraceira; pilla }<\text { pilha }>\text {; } \\
\text { rebo; xapoeiro }<\text { japoeiro }>. . .\end{array}$ \\
\hline B & $\begin{array}{l}\text { Non rexistradas } \\
\text { (ou teñen outros } \\
\text { significados) }\end{array}$ & Si rexistradas & $\begin{array}{l}\text { alargho <largo>; almiñas <alminhas >; } \\
\text { alvitana; badante; bico; caixón } \\
<\text { caixáo }>\text {; cola (de); chapuzada } \\
\text { <chapuçada >; chavascal; } \\
\text { estrompado; reboque (a)... }\end{array}$ \\
\hline C & $\begin{array}{l}\text { Si rexistradas } \\
\text { (nalgúns) }\end{array}$ & $\begin{array}{l}\text { Non rexistradas } \\
\text { (ou teńen outros } \\
\text { significados) }\end{array}$ & $\begin{array}{l}\text { alcouvo }(- \text { alcouve })<\text { alcouve>; } \\
\text { aloque }(\sim \text { aloqueiro }) \text {; atol }(\sim \text { atola }) \text {; } \\
\text { burra; carrucha }(\sim \text { carrocha }) \text {; cocho; } \\
\text { ghabexo <gabejo>; gado a gaño } \\
\text { <ghado a ghanho>; lacada; lavañeira } \\
\text { <lavanheira }>\text {; madre; pampullo } \\
<\text { pampulho >; outeiro; tecelán } \\
\text { <tecelão }>. . .\end{array}$ \\
\hline $\mathbf{D}$ & $\begin{array}{l}\text { Non rexistradas } \\
\text { (ou teńen outros } \\
\text { significados) }\end{array}$ & $\begin{array}{l}\text { Non rexistradas } \\
\text { (ou teñen outros } \\
\text { significados) }\end{array}$ & $\begin{array}{l}\text { bardo }(- \text { barda); cramoeiro; } \\
\text { escouso; óculo; paúlo (de); portiño } \\
<\text { portinho>; regho foreiro <rego } \\
\text { foreiro }>\text {; rei d'aghuas < rei da ághua } \\
(\text { reicinho da água)>; sobrol } \\
(=\text { sobral)... }\end{array}$ \\
\hline
\end{tabular}

Cadro 3. Cognados nos dicionarios

\subsubsection{Palabras rexistradas en (algúns) dicionarios galegos e portugueses ${ }^{20}$}

Alghidar ( - arghidal, alghidal) (sm) 'vaso de barro, cun bordo superior moito maior que o fondo, usado en tarefas domésticas'. Unicamente aparece en Ibáñez (1950) como 'barreño (barcal)'. No GX sen definir, remítese a BARREÑón. Si vén en e-Estraviz. Outras variantes alguidar e alguidal aparecen no $D d D$, e algúns sitúan a palabra en Tui e Goián. E a variante arguidal en Sarmiento (1746-1755c). Nos dicionarios portugueses aparece ALGUIDAR.

Chafarrico (sm) 'posto de bebidas e café nas festas'. Si a recolle e-Estraviz coa variante chafarico 'posto, mesa ou banca dos vendedores nas feiras e romarías'.

${ }^{20}$ Nas páxinas a seguir, as palabras encontradas nas localidades portuguesas van ir marcadas en negra e entre $<>$. En caso de seren variantes, tanto da parte galega como da portuguesa, transcríboas en cursiva negra precedidas de - . Se houber plena coincidencia entre as formas galegas e portuguesas na escrita só poño unha vez a palabra. As entradas dos dicionarios consultados van en VERSALETAS. 
En dicionarios portugueses encontramos as formas CHAFARICA 'taberna, baiuca' (pop.) ou CHAFARrica 'pequeno tasco'.

Defumadouro < defumadoiro $>$ (sm) 'fumazo feito enriba dunha tella con loureiro, xofre, alecrín, allo, ruda e trobisco, con fins máxicos'. Só a rexistra Rivas (2001, Frampas III) e aclara que é do Baixo Miño. Nos dicionarios portugueses vén pero sen aclarar o seu uso máxico.

Empillar <empilhar> (vt) 'facer un monte rectangular ou pilla co esterco das cortes, con broza, restos de comidas, etc. para despois usalo como adubo nos campos'. Unicamente ten o significado de 'apilar'en Pintos (1865c) e García (1985) localízaa en Goián, pero cunha definición incorrecta. Nos dicionarios portugueses si vén como 'amontoar, acumular'.

Fentella $(-$ feitella $)<$ fentelha $\sim$ fontelha $>(s f)$ '(Blechnum spicant) fento coas follas moi finas arredor do cano que nace á beira dos regueiros, en zonas húmidas'. Unicamente vén a variante feitella en García (1985), en Goián. Nos dicionarios portugueses aparece como polipódio, pero semella non ser exactamente o mesmo tipo de fento.

Parceiro(s) (sm) 'compadre(s)'. Franco Grande (1972) defínea como 'pai do xenro'. Tamén no GX e en e-Estraviz. Nalgún dicionario portugués vén como prov. tratamento familiar entre os sogros de um casal.

Perú ( - pirú) (sm) 'pavo’. Recóllena Franco Grande (1972) e García (1985), en Goián. Si está en $e$-Estraviz e no $G X$ aparece como PIRÚ, que remite, sen definir, a PAVO, <piru>.

Poupa (sf), '(Upupa epops) bubela'. Si aparece en varios dicionarios galegos que a sitúan no sur de Pontevedra, en Tomiño, O Rosal, Tui, Salvaterra. Nos portugueses non aclaran en que zona de Portugal se usa máis.

Reboque (a) (loc adv) 'levar a alguén contra a súa vontade: Veu a nai e levouno a reboque'. Unicamente en e-Estraviz ten o mesmo significado que nos dicionarios portugueses, que o definen como 'acto de arrastar' ou 'levar alguém contra a sua vontade'.

Xícara(sf) 'tazapequenadocafé. SiarecollenFilgueiraetalii(1926)e García(1985)na Mezquita. Nos dicionarios portugueses xíCARA aparece coa definición 'pequeno recipiente us. esp. para bebidas quentes, com asa para facilitar a manipulação', o que é máis dubidosa é a súa posible etimoloxía, pois çícara xa está presente no galego medieval. 


\subsubsection{Palabras presentes en (algúns) dicionarios portugueses, pero non están} rexistradas en dicionarios galegos, ou teñen outros significados

Alargho <largo > (sm) 'ensanchamento no lugar onde conflúen varios camiños ou rúas, nun cruce, e que os vecińos usan para pór a secar a palla, a leńa... Son comúns na toponimia desta zona, como o alargo de Portal de Silva (Soutelo). Si aparece recollida nalgúns dicionarios galegos, pero cun significado diferente. Nos portugueses defíneno como 'pequena praza' ou 'num traçado urbanístico, área de dimensão mais espaçosa do que as ruas que interceta’.

Almiñas <alminhas > (sf pl) 'capeliña con figuras das ánimas penando no Purgatorio normalmente no cruce dos camiños e cun peto'. Non está nos dicionarios galegos e nos portugueses aparece como sf pl. 'painel que figura as almas penando no Purgatorio; nicho ou capelinha com esse painel'.

Alvitana (sf) 'cada un dos dous panos exteriores do tresmallo'. Só a encontrei nalgúns traballos sobre a pesca como 'parte da rede'. En dicionarios portugueses defínena como 'rede de malha apertada para não deixar saír o peixe do tresmalho' ou 'no tresmalho cada um dos dois panos exteriores'.

Badante (adx) 'inclinado para dentro (falando de obras de cantería)'. Unicamente referíndose á mesma idea en Otero (1964) e clasifícao como "prov. beir. e minh.». En dicionarios portugueses, 'obra de alvenaria inclinada para dentro'.

Bico (sm) 'extremidade da quilla dos barcos que sobresae na proa'. Os dicionarios galegos non recollen este significado exactamente. En cambio nos portugueses vén como BICO DE PROA 'ponta mais a vante da proa de uma embarcaçáo'.

Caixón <caixão> $(\mathrm{sm})$ 'ataúde'. En dicionarios portugueses é sinónimo de FÉrETRO. Chapuzada <chapuçada $>$ (sf) 'cantidade de auga que se tira a alguén para mollalo'. Non ten ese significado nos dicionarios galegos. En dicionarios portugueses 'quantidade de água que se atira a alguém'.

Cola (de) (loc adv) 'apoio que se pon debaixo da panca para darlle un viro á pedra'. O contrario é pegar a feixe. Unicamente a localicei no vocabulario recollido por Boaventura (1916: 143) 'pedra con que se calça outra pedra maior para se poder volta-la con o auxílio da alavanca ou terro-do-monte».

Estrobo (sm) 'fío que prende o anzol á liña de pescar'. Nos dicionarios galegos non se recolle con este significado. Si está en dicionarios portugueses, escrito con $<v>$. 
Estrompado (adx) 'fatigado despois de moito traballo ou pola moita calor'. Nos dicionarios portugueses si aparece como 'fatigado' (pop.). Unicamente aparece en Otero (1967) aplicado a un animal vello e consumido.

Lavaxe $<$ lavagem $>$ (sf), 'comida para os porcos que se fai coa auga de lavar os pratos da comida'. Nos portugueses vén como sinónimo de LAVADURA, como 'comida para porcos com farelos'.

Silbarbeira $(\sim$ silbalbeira) $<$ gilbalbeira $(\sim$ gibalbeiro, gibaubeiro $)>(s f)$, '(Ruscus aculeatus) pequeno arbusto de froitos vermellos e redondos coma cereixas, coas follas moi duras e picantes; xibarda'. En dicionarios portugueses recollen as variantes GILBARBEIRA Ou GILBARDEIRA, tamén designada como BRUSCA.

\subsubsection{Palabras recollidas en (algúns) dicionarios galegos pero non están en dicionarios portugueses, ou teñen outros significados}

Atol ( $\sim$ atola) (sf), 'monte de terra con pedras ou herbas, que se pon nun rego ou regadoura, co obxectivo de desviar a auga para a rega'. Só en Rivas (1978, Frampas I) aparece algo relacionado: 'Cada uno de los surcos más pequeños que se hacen en la finca para distribuir el agua de riego (Frades y Feiravella). El dicc. refleja atol, con la misma acepción, y atolar, echar el agua por una atol.

Brueira (sf), 'buraco que se deixa nas paredes e valados para paso das augas'. Unicamente aparece en García (1985) e sitúaa en Goián. Nos dicionarios portugueses só localicei a variante BUEIRo 'cano ou buraco para esgoto das águas'.

Burra (sf), 'armazón feita para pescar meixóns no río desde a beira cun arrestón'. Si en García (1985) como 'tinglado para pescar dentro del agua’ en Novefontes e Goián.

Canastrel (sm), 'trampa para cazar paxaros feita con vimbios ou paus'. Unicamente no Apéndice de Rodríguez (1961), que o sitúa en Goián, e en Franco Grande (1972). Nos dicionarios portugueses non ten ese significado.

Carrucha ( - carrocha) (sf), 'roldana dos pozos'. Rivas (1988, Frampas II) sitúa a palabra no Rosal.

Ghabexo < gabejo $>(\mathrm{sm})$, 'calquera recipiente que se usa na vendima'. Unicamente en Rivas (1978, Frampas I), como 'recipiente en xeral 'en Canedo, e Franco Grande (1972), con <v>, en Salvaterra, referido a unha vasilla para o viño. 
Lavañeira <lavanheira> (sf), 'nécora'. Unicamente Ríos Panisse (1977) como sinónimo de nécora, na Guarda, Panxón e Camariñas. Otero (1963 e 1967) e Franco Grande defíneno como 'especie de cangrexo pequeno' na Guarda. Tamén en e-Estraviz.

Madre (sf), 'corda grosa de cánamo que forma parte do espiñel ou palangre'. Unicamente en Rodríguez (1958-1961) e García (1985). Nos dicionarios portugueses non ten ese significado Non encontrei na parte portuguesa o uso de madre como 'peirao feito nos regueiros con pedras ou outros materiais para levar a auga aos muíńos', tal como se di en Sobrada, Taborda e outros lugares de Tomiño. No río Furna e Brines hai varias e teñen cadanseu nome: a madre do Hospital, a madre da Faia...

5.2.4. Palabras non rexistradas en dicionarios galegos e portugueses ou que aparecen con outros significados

Baldranas < mandranas $>$ (sf pl), 'prenda confeccionada polas mulleres raianas para levaren oculto café ou outros produtos de contrabando por debaixo da roupa ou das saias'.

Bardo ( - barda) (sm), 'feixe de argazo'.

Cramoeiro (sm), 'angazo para recoller o argazo cun mango longo de pau'.

Esbuchador (sm), 'aparello de madeira ou doutro material que serve para tirar o anzol da boca do peixe'.

Escouso (sm), 'dise do momento en que a auga do río acabou de baixar e penetra a auga do mar, comeza a repunta: No escouso da maré .

Léitaras (sf pl), 'gónadas dos sables, usadas en culinaria para facer os debullos'. Óculo (sm), 'buraco de entrada de unha mina de auga'.

Paulo (de) (loc adx, loc adv), 'dise do terreo ou prado que se deixa varios anos sen traballar, en descanso, de pousío’.

Regho foreiro <rego foreiro $>$ ( $\mathrm{sm}$ ), 'rego por onde se desvían as augas dos camiños da parroquia para que non entren nos eidos das casas'.

Rei d'aghuas <rei da água ( $\sim$ reicinho da água) $>(\mathrm{sm})$, '(Alcedo atthis) picapeixe'. En portugués hai unha variante REI-DO-MAR como sinónimo de PICA-PEIXE. 
Sobrol ( sobral) (sm), 'efecto óptico que se produce cando entra a auga do mar e desauga o río; a auga do mar vai polo fondo e brilla. Nese momento non se pode pescar moi ben porque a rede queda na horizontal'.

\section{GLOSARIO}

Neste glosario recollo tanto palabras encontradas en diferentes inquéritos feitos para este e outros traballos anteriores como o peneirado noutros glosarios e obras en que se cita vocabulario desta zona. Como xa comentei noutras ocasións, nesta área lingüística a localización dos termos non é xeral nin uniforme pois tanto na parte galega como na portuguesa as respostas tanto poden corresponder a unha área compacta e restrinxida, como sucede entre localidades do concello de Tomińo e Vila Nova de Cerveira ou entre Tui e Valença, como apareceren en lugares distantes sen apenas conexión, como no Rosal e Valença. Procuro pór unicamente o nome da parroquia e freguesía e non o nome do concello (xa indicados na nota 9). Se non menciono o lugar onde localicei a palabra, enténdase que foi unha resposta máis frecuente e común. Evito no posible unha localización complexa e repetitiva. As formas recollidas na parte portuguesa van marcadas entre $<>$ e calquera das variantes precedidas de $\sim$. Non inclúo de novo as palabras explicadas na epígrafe 5.2.

\subsection{Flora e fauna}

\subsubsection{Plantas}

Fruncho (sm) (Foeniculum vulgare) nas Eiras e Goián e en Ganfei, - funcho en Malvas, Cerdal e Sopo.

Lingua de ovella ( ouvella) (sf) (Plantago lanceolata) en Goián, Eiras, Malvas; <língua de ovelha> en Sopo e Campos.

Matafogho (sm) (Fumaria officinalis) nas Eiras, Goián e Soutelo; <matafogo> en Sopo e Cerdal.

Pampullo (sm) (Chrysantemum myconis), <pampulho $>$.

Poexo (sf) (da familia Lamiaceae, é diferente á hortelán), <poejo $>$.

Prixel (sm) (Petroselinum crispum) perrexel en Goián e Sopo; noutras localidades portuguesas din salsa. 
Vinagreira (sf) (Phytolacca decandra) en Mabia (Oia) e en Sopo. Tamén é coñecida na parte galega como grana, en Soutelo (Salceda de Caselas) e Malvas; cacho de grana, en Porto (Salvaterra); e cachopinto, en Goián.

\subsection{2. Árbores}

Abruñeiro (sm) (Prunus spinosa) ( $\sim$ abruño), <abrunheiro ( $\sim$ abrunbo) $>$. Amial (sm) 'conxunto de amieiros', en Goián e Campos.

Escambrueiro (sm) (Crataegus monogyna) 'arbusto espiñoso, estripeiro' en Soutelo (Salceda de Caselas), <escramboeiro > en Cerdal.

Noceiro (sm) 'nogueira' en Goián; <noceira> (sf) en Campos.

Sangriño (sm) (Rhamnus frangula) en Goián ( zanquiño en Soutelo (Salceda de Caselas)), <sangarinho > en Sopo.

Tanxerineiro $(\mathrm{sm})<$ tangerineiro $>$.

Xapoeiro (sm) 'camelio', <japoeiro > en Sopo, e non como no portugués padrón japoneira.

Gharuma (sf) 'folla do piñeiro' en Goián, <caruma> en Cerdal e Campos; tamén chamada pico, en Caldelas e Ganfei.

\subsubsection{Insectos}

Cadela de frade (sf) (Forficula auricularia) 'forcadela' en Goián e Sopo.

Carroucho (sm) (Lucanus cervu) 'escornabois' en Goián e As Eiras, <carrocho ( - carrocha, - carroicha $)>$ en Campos e Sopo.

Liscoranzo (sm) (Anguis fragilis) 'escáncer, liscanzo' en Goián, <liscranço ( - licranço) > en Sopo e Campos. Tamén coñecido como seghavivos (en Soutelo (Salceda de Caselas)).

Saltón (sm) <saltáo > en Campos, Sopo e Ganfei.

\subsubsection{Paxaros}

Carriza (sf) (Troglodytes troglodytes), < carriça ( carricinha) > en Sopo.

Escribidor (sm) (Emberiza cirlus) en Goián e Soutelo (Salceda de Caselas), <escrevedeira> en Campos e Sopo. 
Papafighos (sm pl) (Oriolus oriolus) en Goián, Soutelo (Salceda de Caselas), <papafigos> en Campos, Sopo e Ganfei.

Pedreiro (sm) (Apus apus) en Goián, Sopo, Campos, Ganfei.

Pintasilgo (sm) (Carduelis carduelis) en Goián, <pintassilgo> en Campos e Sopo ( - pintasilva - pintasiurva en Sopo).

Tecelán $(\mathrm{sm})$ 'ave de rapina semellante ao gabián' en Goián, <tecelão> en Sopo $(\sim$ tecedeira en Campos.

\subsubsection{Animais terrestres}

Martaraña (sf) (Martes martes), <martaranho> $(\mathrm{sm})$ en Campos ( $\sim$ mataranho en Sopo).

Tourón (sm) (Mustela putorius) 'mamífero mustélido' en Goián e Eiras, <touró> en Sopo.

Xirico $(\mathrm{sm})$ ‘burriño’ en Goián e As Eiras, <jerico $(-$ jirico $)>$.

6.1.6. Algas

$\operatorname{Argazo}(\mathrm{sm})$ 'alga mariña castaña', <argaço $(-$ sargaço $)>$.

Botella (sf) 'tipo de alga coa que alimentaban os porcos' en Camposancos, $<$ botelha> en Caminha.

Labaza (sf) 'alga do río de follas verdes e talos longos', <labaça>.

\subsection{Actividades laborais}

\subsubsection{Agricultura}

Bardeiro (sm) 'monte grande de palla na eira para alimentar o gado; palleiro'.

Cabedullo (sm) 'franxa de terreo na cabeceira dunha leira que se ara ao través' nas Eiras, <cabedulho > en Campos.

Camballón (sm) 'rego fondo para plantar a viña', 'lombo de terra entre dous sucos' ( camallón, nas Eiras), <camalló >.

Coucón (sm) 'peza alongada do carro sobre as que xira o eixe', <coucó >.

Curucho (sm) 'parte superior do palleiro ou meda'. 
Espalladoira (sf), 'forquita para manexar a herba', <espalhadoira>.

Ghado a gańo $(\mathrm{sm})$ 'cría e coidado das vacas a medias entre o feirante e o labrego' (o feirante deixa o gado, que é da súa propiedade, aos labregos para que llo coiden, e van a medias nas crías e na venda), < gado a ganho $>$.

Meda (sf) 'monte grande de palla na eira para alimentar o gado'.

Terrón ( - torrón $)(\mathrm{sm})$ 'pedazo de terra compacta que non se desagrega a non ser que o golpees coa aixada', <terró $>$.

\subsubsection{Viña (cf. Pousa 2004)}

Canteiros (sm pl) 'trabes de madeira onde se pousan os bocois na bodega'.

Espicha (sf) 'pequeno buraco nos barrís, que se tapa cunha cana ou cun pauciño; o mesmo pauciño que tapa o buraco'.

Fundo $(\sim$ fondo $)(\mathrm{sm})<$ fundo $>$. Distínguese fundo como substantivo e fondo como adxectivo: No fundo do mar; un río fondo.

Fuste (sm) 'barril de gran tamaño, de máis de 50 cabazos, maior ca un bocoi; en plural, conxunto dos barrís dunha adega'.

Ladroar ( - desladroar) (vt) 'tirar os ladróns e as follas que prexudican a viña'.

Lata ( - latada) (sf) 'viña alta feita con paus e esteos'.

Leiva (sf) 'táboa curva dos barrís, doela'.

Loureiro (sm) 'caste de uva'.

Morto (sm) 'gran pedra afundida na terra que axuda a suxeitar o entramado da viña'.

Testeiro $(\mathrm{sm})$ 'traveso que se pon na cabeceira das viñas', (<- testeira $>)$.

Trousa (sf) 'acción de trousar'.

Trousar (vt) 'trasegar o viño'.

Treixadura (sf) 'caste de uva'.

Xabre $(\mathrm{sm})$ 'encaixe ou suco nos barrís para asegurar os fondos', <javre >.

\subsubsection{Pesca no río (cf. Pousa 2002)}

Alcharife ( $\sim$ alxarife $)(\mathrm{sm})$ 'rede de arrastre desde terra, tirada por grupos de pescadores que se asociaban en compañías chamadas quebradas', $<$ algerife $>^{21}$.

\footnotetext{
${ }^{21}$ Nos dicionarios portugueses indícase que é usada polos pescadores do Miño.
} 
Debullos (sm pl) 'comida feita cos miúdos do sable e arroz ou patacas', $<$ debulhos $>$

Lampreeira (sf) 'rede para pescar lampreas'.

Míllaras (sf pl) 'ovas do peixe', <mílharas $>$.

Negrón (sm) 'tipo de muxo', <negrão >.

Menina (sf) 'subespecie de sable que non pasa de dous quilos'.

Muxeira (sf) 'rede para muxos', <mugeira>.

Pandullo (sm) 'saquiño con area, con brugal, que se pon nas redes para que vaian ao fondo', <pandulho $>$.

Promesa (sf) 'salmón de má calidade' ( - tranca), < promessa $>$.

Sabella (sf) 'peixe diferente ao sable, máis plano e pequeno'. Tamén lle chaman xerela, <savelha $>$.

Samborgha 'peixe parecido ao sable', <samborga $>$.

Solleira (sf) <solheira> 'rede para pescar a solla'.

Taína (sf) 'nome dado a un tipo de muxo que acostuma dar tres saltos fóra da auga', <taínha $>$.

Tela $(\mathrm{sf})(\operatorname{con} / \varepsilon /)$ 'rede para pescar o meixón'.

\subsubsection{Pesca no mar}

Baeta (sf) 'tipo de cangrexo de roca'.

Brughal (sm) 'lugar no fondo do mar onde hai area grosa e restos de cunchas; a mesma area grosa' $<$ brugal $>$.

Callau (sm) 'pedra que se puña nas redes antes de usar o chumbo', <calhau $>$.

Camboa (sf) 'tipo de pesqueira na costa que se enche de auga cando sobe a marea e onde quedan atrapados os peixes cando baixa'.

Ferro $(\mathrm{sm})$ 'áncora de dúas ou tres puntas'.

Foda (con /o/), 'peixe agulla moi grande'.

Pateiro 'peixe cuncho'.

Pau de ré $(\mathrm{sm})$ 'o último buraco de popa'.

Polbo (sm) 'Octopus vulgaris', $<$ porbo $>$ (non pronuncian $<$ v $>$ na zona portuguesa). 
Pousamastro (sm) 'peza da gamela'.

Rasco (sm) 'rede de tres panos para pescar budións, robalos, maragotas...'.

Sacho (sm) 'tipo de áncora feita de pedra e madeira'.

\subsubsection{O contrabando}

Zocata (sf) en Camposancos, <sucata> en Caminha. Chámanlle así ao contrabando que se facía nesta parte do Miño, entre Caminha e A Guarda. Na zona de Goián é cońecido como o pisco, e en Valença como trapiche.

\subsection{O territorio}

\subsubsection{As augas}

Chea (sf) 'enchente do río, forte subida das augas que provoca inundacións', $<$ cheia $>$.

Enxurro ( enxurrada) (sm) 'corrente impetuosa de augas ou outro líquido polos camiños'.

Esteiro 'regueiro pequeno que desemboca no río Miño'.

Levada ( - lovada) (sf) 'corrente de auga que vai regando campos ou dando movemento aos moíńos; a mesma canle por onde pasa a auga'.

Poza (sf) 'represa de auga artificial cun ollo por onde sae a auga para regar o millo e hortas', <poça $>$.

\subsubsection{Accidentes terrestres}

Areo (sm) 'illa no río Miño só de area por depósito fluvial, sen vexetación', $<$ areio $>$.

Insua (sf) 'terreo rodeado de auga á beira do río; illa na desembocadura do Miño'. Lacada (sf) 'foxa nos camiños'.

Morraceira (sf) 'illa que se forma por depósito de area no último tramo do Miño, e ten xa algo de vexetación, con xuncos'; en pt. tamén < morra - murra $>$.

Regheira (sf)'lugar costento e fondo nas abas do monte por onde decorren as augas'; 'fondonada encharcada, húmida onde nace un reguiño de auga todo o ano'. Regheiro (sm) 'corrente de auga'. 
Portiño $(\mathrm{sm})$ 'enseada pequena no mar protexida dos ventos, onde poden atracar as gamelas', ao longo da costa hai moitos e teñen cadanseu nome: $O$ portiño do Santo..., < portinho $>$.

Reza $(-$ resa) $(\mathrm{sf})$ 'curva pronunciada que se forma nos areos ou nas praias, como a de Camposancos, por acción das mareas, e onde a auga dá volta’, <reça>.

Seco (sm) 'baixo', no mar.

Rebanceira (sf) 'vagoada con pendente lixeira' en Areas, <ribanceira> en Ganfei.

\subsubsection{Tipos de terreos}

Aloque $^{22}$ ( aloqueiro, $\sim$ aloco $)(\mathrm{sm})$ 'terreo movedizo con moita auga e a terra branda'.

Alocarse (vi) <alocar-se > 'enterrarse nun aloqueiro'.

Baldío (sm) 'monte comunal ou terreo comunal que é usado colectivamente'. Tamén está presente en moitos topónimos na zona, como O Baldío da Moura.

Barxe ( - barxa) (sf) 'terreo agrícola moi produtivo á beira dun río ou regueiro', $<$ varge $>$. Como topónimo é moi abundante.

Bouza (sf) 'terreo no monte, que pode estar cerrado ou non, especialmente con toxo e árbores, ou para outros usos', <bouça >. Moi presente na toponimia (Bouza Valada, Bouza Fría...).

Chan (sf) 'planicie grande na parte supeiror do monte, terreo chan no alto do monte', <chã $>$. A palabra está presente en moitos topónimos da zona.

Chavascal (sm) 'terreo malo, improductivo, con moitas silvas, toxos...'.

Cocho $(\mathrm{sm})(/ \mathrm{o} /)$ 'terreo de escasas dimensións dedicado ao cultivo de patatas, verzas...'.

Escampado (sm) 'terreo sen vexetación, deshabitado, terreo baldío sen cultivar'. Leira (sf) 'calquera terreo de cultivo'.

${ }^{22}$ Esta palabra aparece en varios documentos medievais como, por exemplo, un citado por Vila-Botanes (2001: 77 e 78) no que se reflicten os preitos do cabido cos zapateiros e curtidores que tiñan pelamios e aloques: «dos ditos palamos e aloques [...] agora nobamente feitos que eran em dano dos camynnos e redondava mal a todos camynnantes e carros e bestas...», "por quanto estes aloques e palamos [...] teen seus coiros acortir con casca...». 
Campo (sf) 'terreo dedicado ao cultivo'. Poderiamos trazar unha isoglosa entre as parroquias tendo en conta o uso da palabra leira/campo. Esta lińa pasaría por Malvas e Ganfei, onde se usa campo, fronte a parroquias de Tomiño, O Rosal en que se di leira.

Ribeira (sf) 'terras de cultivo preto da beira do Miño', <ribeiras> (sf pl) en Ganfei.

Tomada (sf) 'terreo grande no monte, en moitos casos pechado con valados, e dedicado ao cultivo de pińeiros e outras árbores'. Forma parte de moitos topónimos da zona.

Veigha (sf) 'conxunto de campos de cultivo, extensión ampla de terra cha froito dos depósitos aluviais, como a Veiga de Ganfei ou a Veiga do Louro', <veiga>.

\subsubsection{Tipos de pedras}

Esteo $(\mathrm{sm})$ 'pedra rectangular en forma de columna con que se ampara ou sostén algo, especialmente a viña', <esteio $>$.

Outeiro (sm) 'penedo de grandes dimensións na costa ou no monte'. Tamén se utiliza para referirse a montes pequenos ou elevacións pouco pronunciadas do terreo.

Pasadoiras (sf $\mathrm{pl}$ ) 'pedras que se poñen nos regatos ou regueiros para o paso das persoas, poldras', <passadeiras $>$.

\subsection{A casa e construcións adxectivas}

Cabanón (sm) 'alboio grande onde se garda o carro, a palla...', < <abanố>.

Eido (sm) 'terreo de cultivo, normalmente arredor da casa'.

Canizo (sm) 'hórreo fixo feito de pedra ou madeira', <caniço>.

Quinteiro (sm) 'cuberto con paredes e tellado á entrada do eido da casa onde se garda o carro e os animais'.

Rosío ( resío, - rocio) ( $\mathrm{sm}$ ) 'franxa de terreo arredor das casas onde cae a auga do tellado', que limita a propiedade, $<$ rossio $>$.

Tanque $(\mathrm{sm})$ 'construción para lavar a roupa, cuberta con tellado ao lado do pozo ou dun regueiro; lavadouro'. 


\subsection{O corpo humano}

A maior parte deste vocabulario púideno consultar no $A L G a$ (vol. V, 2005) e seleccionei aquelas palabras que nesta zona se din igual ca no portugués (popular ou estándar).

\subsubsection{Aspectos fisicos}

Acordar ( alcordar) (vi) 'espertar' (ALGa: V 267, especialmente Pontevedra sur e Ourense).

Bochecha (sf) 'fazula' (ALGa: V 38b, en P29, P32, P33).

Cabelo (sm) (ALGa: V 6, en P32, P33 no BM e máis lugares no sur de Pontevedra e sur de Ourense).

Carrapicho (sm) 'madeixa de cabelo que fai un caracol' (ALGa: V 107, en P30, aínda que como 'crecho').

Cóchicas ( - cuchicas) (sf pl) 'cóxegas' (ALGa: V 226, só na Guarda, P33).

Cotobelo (sm) en Goián ( $A L G a$ : V 47, con /e/ en P25 e maiormente no sur de Ourense); $<$ cotovelo $>$ nesta zona pronúnciase con $<\mathrm{b}>$.

Empixes ( - empixas) (sf $\mathrm{mf}$ en $\mathrm{pl}$ ); en galego cartografiouse empixa en P29, e empinxes en O11 (ALGa: V 161a); con outro uso en O31 (ALGa: V 165), <empirxas $>$ (corresponde a IMPIGENS en portugués).

Engurricha (sf) úsase en máis lugares ca no P32 sinalado no ALGa: V 4.

Espirro (sm) 'esbirro'; o verbo espirrar localízase no sur de Pontevedra e Ourense, segundo se observa no $A L G a$ : V 204.

Ollar (vt) (ALGa: V 196, en P28, P29 e varios puntos de Ourense). En Soutelo (Salceda de Caselas) é frecuente ollar de como 'coidar, vixiar', <olhar>.

Tomates (sm pl) (pop.) 'testículos'.

Tornecelo ( tornocelo) (sm) 'nocello, nortello' (ALGa: V 75, o primeiro en P28, P29, P32, P33 do BM e poucos máis; a segunda forma en P18, P28, P31 e O31), $<$ tornozelo $>$.

Torzollo (sm) 'tirizó' (ALGa: V 121, en P31, P32, P33), <torzolho>.

Xoello (sm) en Goián (ALGa: V 71, en P23; como xiollo en P22, P25 e P32), $<$ joelho $>$. 


\subsubsection{Adxectivos caracterizadores}

Aghoniado -a 'con malestar xeral, que se encontra mal e non pode describilo', $<$ agoniado $>$.

Aghoado -a 'que anda con ganas de algo', <agoado $>$.

Alabarado $-\mathbf{a}^{23}$ 'persoa que anda ou fai as cousas ás présas, que sempre anda acelerado'.

Aleixado -a 'magoado nos brazos ou pernas, lesionado', <aleijado $>$.

Careco -a 'calvo' ( $A L G a$ : V 99, en P22, 29, 30 e 32).

Fanado -a 'sen algún dente' ( $A L G a$ : V 125, no BM e outros puntos do sur de Pontevedra).

Cambicho -a 'escarranchado' en Soutelo e Valença ( $A L G a$ : V 136, en P29), ten as pernas cambichas. Tamén o verbo cambichar (vi) 'meter unha perna para adentro ao andar', cambicha ao andar.

Cañoto -a (m.f. en masc.) 'que usa a man esquerda', frecuente no BM ( $A L G a$ : V 137, só O31), < canhoto>.

Cunico - conico $-\mathbf{a}^{24}$ 'tacaño, nada espléndido, que anda con cunichadas'.

Enghurrichado $-\mathbf{a}^{25}$ 'dise do que ten moitas engurras ou engurrichas' <engurrichado>.

Esfurricado -a 'que ten cagarría'. Tamén o verbo esfurricarse e o substantivo furriqueira ( $A L G a$ : V 169, só en 3 puntos do sur).

Fadista 'individuo que gusta de ir ben vestido e peiteado, presumido e chulo'.

Lambido -a 'excesivamente presumido ou exquisito'.

Marreco -a 'chepudo' (ALGa: V 140, en P29, P30 e O31 con /e/; con/ع/ en P25, P27 e O28).

Sacana 'que lle gusta facer bromas, brincadeiras'.

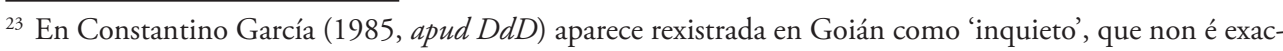
tamente o significado que cońecemos e documentamos.

${ }^{24}$ Constantino García sitúa esta palabra en Goián (Tomiño) ( $D d D$ : s.v.).

${ }^{25}$ No Apéndice ó Dicionario de Eladio Rodríguez (1961) localízase a palabra en Tebra (Tomiño) (DdD: s.v.).
} 


\subsection{Pares léxicos con significados especializados}

Unha das diferenzas máis complexas de determinar entre o portugués e o galego actual é o uso que facemos cando temos parellas de palabras con significados moi próximos pero cunha especialización semántica diferente ou cunha frecuencia de uso distinta. Esta análise é difícil de facer utilizando unicamente o método das enquisas directas. Como sinala Philippe Humblé (2005-2006: 2) trátase de un tipo de palabras que forman parellas en cada unha das linguas, con acepcións aparentemente idénticas, pero que funcionan en realidade con restriccións gramaticais ou léxicas diferentes. Para analizar o seu uso cómpre partir dun corpus textual (oral) amplo, co que non conto nestes momentos, a través do que se poida comprobar exactamente como se usan e en que contextos e captar as restricións naturais feitas na fala espontánea.

Vou pór só uns cantos exemplos nos que podo establecer a súa diferenza tendo en conta que sei como se usan, normalmente, nesta zona:

empurrar 'dar empurróns, con movementos que pretenden afastar, para adiante' (non me empurres) $\neq$ puxar 'tirar ou mover para si' (puxa pola corda).

fogo 'incendio' ( hai fogo no monte) $\neq$ lume 'fogo que se acendeu para utilidade na cociña; substancia en combustión' (alcende o lume do fogón) .

pinchar 'dar pinchos, saltar' (pinchou por riba do valado coma se nada) $\neq$ picar 'ferir con un obxecto aguzado, que causa proído, comichón' (piqueime coa roseira, a bicicleta ten a roda picada).

virar 'mudar de un lado para outro a dirección ou a posición' (viroume as costas, vira o testo) $\neq$ xirar 'dar voltas arredor do seu eixo' (a carrucha xira sen parar).

Coma estes casos hai que investigar e perfilar o uso de moitas outras parellas como apañarl coller, contestarl responder, diferentel distinto, mall apenas, partirlromper, etc. Penso que é importante analizar a polisemia destes casos na nosa lingua e como se debe presentar nos nosos dicionarios de uso e, como non, despexar as dúbidas das posibles interferencias do castelán. 


\section{CONCLUSIÓNS}

En resumo, neste escenario o que máis compartimos é a fala, pero oímonos como estraños. Algúns vemos as proximidades, outros as diferenzas. Vivimos nunha fronteira sen vocación de separarnos, unha isopolítica que nunca chegou a ser unha isoglosa sen fracturas. Camiñamos uns a rente dos outros e recibimos informacións desiguais, o que nos impide comprendernos de verdade.

E así como nunha investigación lingüística a nivel morfolóxico ou fónico é 'doado' delimitar o que nos distingue ou o que nos une, cando tratamos o léxico non se pode chegar a establecer unha conclusión tan clara. Tratar de investigar e estudar o léxico polisémico é o conto de nunca acabar. O que é innegable é que hai unha enorme variación e variabilidade léxica en ambas as marxes da fronteira miñota; mais esta non é unha característica máis acentuada na parte galega por manterse a nosa lingua máis tempo sen normalizar (e sen normativizar).

É necesario seguir facendo traballos léxicos que axuden a arrequentar o léxico dicionarizado ${ }^{26}$, pois talvez poidan axudar a despexar dúbidas canto ao uso e selección de termos na norma galega e á fixación da súa verdadeira polisemia fronte ao castelán.

Moitas destas palabras están condenadas á morte segundo cambian os costumes e as formas de vida, pero paga a pena recoller o léxico vivo, os nomes das cousas, por moi sinxelas que parezan.

\section{REFERENCIAS BIBLIOGRÁFICAS}

$A L G a=$ García, Constantino / Antón SANTAMARIna (dirs.) (1990): Volume I: Morfoloxía verbal. A Coruña: Fundación Barrié / Instituto da Lingua Galega.

$A L G a=$ García, Constantino / Antón SANTAMARINa (dirs.) (1995): Volume II: Morfoloxía non verbal. Santiago de Compostela: Fundación Barrié / Instituto da Lingua Galega.

ALGa = García, Constantino / Antón Santamarina (dirs.) (2005): Volume V: Léxico. O ser humano (I). Santiago de Compostela: Fundación Barrié / Instituto da Lingua Galega.

Alonso, Eliseo (1987): Gamelas y marineros. A Guarda: Diputación Provincial de Pontevedra / Imprenta J. Vicente.

Alonso, Eliseo (1989): Pescadores del río Miño (Tramo gallego-portugués). Vigo: Diputación Provincial de Pontevedra.

${ }^{26}$ Aínda que xa sabemos como ben di Sequeira (1957/58: 140): «O facto de inclusão no dicionário não basta para lhes generalizar o emprego». 
Alonso Estraviz, Isaac (dir.) (2005): Dicionário da Lingua Galego-Portuguesa, e-Estraviz. Portal Galego da Língua. Dispoñible en lińa: http://www.estraviz.org/.

Boaventura, Manuel (1916): Vocabulário Minhoto. I vol. Espozende: Tipografia Espozendense de José da Silva Vieira.

Carita, Ma de Lourdes (1999): Heterossemânticos/Heterosemánticos: "Falsos amigos» entre o Português e o Espanhol. Viana do Castelo: Instituto de Inovação Educacional / Tipografia Sousa.

Carballeira Anllo, Xosé María (coord.) (2000): Gran Diccionario Xerais da Lingua. Vigo: Edicións Xerais.

Casteleiro, João Malaca (coord.) (2011): Dicionário da Língua Portuguesa Contemporânea, vol. I e iI. Lisboa: Acadêmia das Ciências de Lisboa / Fundaçấo Calouste Gulbenkian / Editorial Verbo.

Cintra, Geraldo (1998): «Cognados: Sistematização e Implicaçōes», Cadernos do Centro de Linguas 2, 137-142.

Costa, Joaquim Almeida / Melo, A. Sampaio e (19795): Dicionário da Lingua Portuguesa. Porto: Porto Editora.

$D d D=$ Santamarina, Antón (ed.) (2006-2013).

DPLP = Dicionário Priberam da Lingua Portuguesa, 2008-2013. Dispoñible en liña: http://www.priberam. $\mathrm{pt} / \mathrm{dlpo} /$.

e-Estraviz = Alonso Estraviz, Isaac (2005).

Ericeira, Luís de Meneses, conde da (1946): História de Portugal Restaurado. Porto: Livraria Civilização.

Dispońible en liña: https://archive.org/details/bhistriadeportu01eric.

Fernández Rodríguez, Manuel (I995): Goián. Estudio histórico. Santiago: Xunta de Galicia / Consellería de Cultura.

Fernández Santomé, Xerardo (2012): Treboada galega. Vigo: Asociación Folc. Gaiteiros da Xistra / Gráficas Bouzas.

Ferreira, Aurélio Bunarque de Holanda (2010): Dicionário Aurélio da Lingua Portuguesa. O Brasil: Editora Positivo. Dispońible en lińa: http://www.dicionariodoaurelio.com/.

Figueiredo, Cândido de (2007): Novo Diccionário da Lingua Portuguesa. Dispoñible en lińa: http://www. dicionarioaberto.net).

García, Constantino (1985), Glosario de voces galegas de hoxe. Anexo 27 de Verba. Santiago de Compostela: Universidade de Santiago de Compostela.

Garrido rodríguez, Jaime (2001): Fortalezas de la antigua provincia de Tuy. Vigo: Deputación de Pontevedra.

Guerreiro, Castro (2006): Contributos para a História de Vila Nova de Cerveira III, Artes-Pescadores e Espécies do Rio Minho. Tui: Gráficas Juvia.

$G X=$ Carballeira Anllo, Xosé María (2000).

Houarss, Antônio (2011): Dicionário de Português Atual Houaiss. Círculo de Leitores e Sociedade Houaiss / Ediçôes Culturais. Dispoñible en liña: http://houaiss.uol.com.br/.

Humblé, Philippe (2005): «Falsos cognados. Falsos problemas. Un aspecto de la enseñanza del español en Brasil», Revista de Lexicografia 12, 197-207.

Leite de Vasconcellos, José (1970): Esquisse d’une Dialectologie Portugaise. 2a ed. Lisboa: Centro de Estudos de Lisboa.

Macedo, António de Souza de (I663): Mercúrio Portuguez com as novas da guerra entre Portugal e CasteIla. Lisboa: Biblioteca Nacional. Res-110 V. Dispoñible en liña: http://purl.pt/12044/6/res-110-v_PDF/ res-110-v_PDF).

Martínez Pousa, Cristal (2009): Arquitectura e os indianos en A Guarda, O Rosal e Tomiño: proposta de catalogación. Traballo Academicamente Dirixido. Facultade de Xeografía e Historia, Universidade de Santiago de Compostela (inédito). 
Merino, Baltasar (1906): Flora descriptiva e ilustrada de Galicia. Tomo II. Santiago de Compostela: Tipografía Galaica.

Mörling, Staffan (1989): As embarcacións tradicionais de Galicia. Noia: Consellería de Pesca / Gráficas Sementeira.

Netto, Ma Teresa De M. Lino (1949): A linguagem dos pescadores e lavradores do concelho de Vila do Conde. Separata da Revista Portuguesa de Filologia, vols. I e II. Coimbra: Casa do Castelo Editora.

Pousa Ortega, Helena (2002): «Léxico fronteirizo no Baixo Miño: a pesca con barco», en Rosario Álvarez / Francisco Dubert / Xulio Sousa (eds.), Dialectoloxía e Léxico. Santiago de Compostela: Consello da Cultura Galega / Instituto da Lingua Galega. Dispoñible en liña: http://www.consellodacultura.org/ mediateca/pubs.pdf/dialectoloxia.pdf.

Pousa Ortega, Helena (2004): "Que escoita o Miño camiño da Guarda?», Animal+ 15, 24-25.

Rego, Aurora ВотÁo (2013): «A mobilidade galega a partir da raia minhota portuguesa (séculos XVII-XIX). A fixação no concelho de Caminha», X Congreso Asociación Demografía Histórica. Albacete, 18 al 21 de junio de 2013. Dispońible en lińa: xcongresoadeh2013.sched.org/speaker/aurorarego.

Rego, Aurora Botão (2009): «A fixação de uma comunidade piscatória galega em Vila Praia de Âncora. Abordagem de alguns comportamentos demográficos e sociais no século XIX», en Isidro Dubert / Hortensio Sobrado Correa (eds.), El Mar en los siglos Modernos. Santiago de Compostela: Xunta de Galicia, 149-168.

Rego, Aurora Botão (2010): «A fixação de galegos na zona ribeirinha de Viana do Castelo», en IX Congresso da Associação de Demografia Histórica. Ponta Delgada: Universidade dos Açores.

Ríos PANisse, Ma del Carmen (1977): Nomenclatura de la flora y fauna maritimas de Galicia, I Invertebrados y peces. Anejo 7 de Verba. Santiago de Compostela: Universidade de Santiago de Compostela.

Santamarina, Antón (ed.) (2006-2013): Dicionario de dicionarios. Corpus lexicográfico da lingua galega. Santiago de Compostela: Instituto da Lingua Galega / Seminario de Lingüística Informática - Grupo TALG. Dispoñible en lińa: http://sli.uvigo.es/DdD/.

Sequeira, Francisco Júlio Martins (1957/1958): Apontamentos acerca do Falar do Baixo-Minho. Lisboa: Revista de Portugal.

VILA-Botanes, Suso (2001): Tui e Valença nos séculos XI a XV. Os acontecementos históricos, sociais, artísticos e económicos. O Porriño: Asociación de Amigos da Catedral de Tui / Gráficas Rofer.

VOLGA = Instituto da Lingua Galega / Real Academia Galega (1989): Vocabulario ortográfico da lingua galega . Santiago. Dispoñible en liña: http://www.realacademiagalega.org/recursos-volg. 